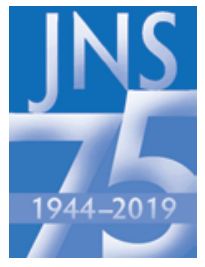

\title{
Recent advances in the management of cervical spondylotic myelopathy: bibliometric analysis and surgical perspectives
}

\author{
JNSPG 75th Anniversary Invited Review Article
Yu-Chun Chen, MD, PhD, ${ }^{1-3}$ Chao-Hung Kuo, MD, ${ }^{1,4,5}$ Chieh-Ming Cheng, MD, ${ }^{4}$ and Jau-Ching Wu, MD, PhD ${ }^{1,4}$

${ }^{1}$ School of Medicine, National Yang-Ming University, Taipei; ${ }^{2}$ Department of Family Medicine, Taipei Veterans General Hospital; ${ }^{3}$ Institute of Hospital and Health Care Administration, National Yang-Ming University, Taipei; ${ }^{4}$ Department of Neurosurgery, Neurological Institute, Taipei Veterans General Hospital; and ${ }^{5}$ Department of Biomedical Engineering, School of Biomedical Science and Engineering, National Yang-Ming University, Taipei, Taiwan

OBJECTIVE Cervical spondylotic myelopathy (CSM) has become a prevalent cause of spinal cord dysfunction among the aging population worldwide. Although great strides have been made in spine surgery in past decades, the optimal timing and surgical strategy to treat CSM have remained controversial. In this article the authors aimed to analyze the current trends in studies of CSM and to summarize the recent advances of surgical techniques in its treatment.

METHODS The PubMed database was searched using the keywords pertaining to CSM in human studies that were published between 1975 and 2018. Analyses of both the bibliometrics and contents, including the types of papers, authors, affiliations and countries, number of patients, and the surgical approaches were conducted. A systematic review of the literature was also performed with emphasis on the diagnosis and treatment of mild CSM.

RESULTS A total of 1008 papers published during the span of 44 years were analyzed. These CSM studies mainly focused on the natural history, diagnosis, and treatment, and only a few prospective randomized trials were reported. For the authors and affiliations, there was a shift of clustering of papers toward Asian countries in the past decades. Regarding the treatment for CSM, there was an exponential growth of surgical series published, and there was a trend toward slightly more anterior than posterior approaches through the past decade. Patients with CSM had increased risks of neurological deterioration or spinal cord injury with nonoperative management. Because surgery might reduce the risks, and early surgery was likely to be correlated with better outcomes, there was a trend toward attention to mildly symptomatic CSM.

CONCLUSIONS There is emerging enthusiasm for research on CSM worldwide, with more publications originating in Asian countries over the past few decades. The surgical management of CSM is evolving continuously toward early and anterior approaches. More prospective investigations on the optimal timing and choices of surgery are therefore needed. https://thejns.org/doi/abs/10.3171/2019.5.SPINE18769

KEYWORDS cervical spondylotic myelopathy; CSM; bibliometrics; spinal cord injury; SCl; ossification of posterior longitudinal ligament; OPLL; cervical disc arthroplasty; CDA

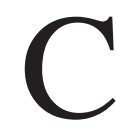
ERVICAL spondylotic myelopathy (CSM) has become a prevalent cause of spinal cord dysfunction among the aging population worldwide. There is a wide spectrum of symptoms and neurological signs associated with CSM. The common presentations of this degenerative cervical myelopathy may vary from slight dysesthesia to quadriparesis and severe sphincter dysfunction. ${ }^{32,41,59,60}$ There are frequently associated cervical spine pathologies such as intervertebral disc herniation, degenerative disc disease, ligamentum flavum hypertrophy,

ABBREVIATIONS ACCF = anterior cervical discectomy and corpectomy with fusion; ACDF = anterior cervical discectomy and fusion; CDA = cervical disc arthroplasty; $\mathrm{CSM}$ = cervical spondylotic myelopathy; $\mathrm{MCC}=$ maximum canal compromise; $\mathrm{MEP}=$ motor evoked potential; mJOA = modified Japanese Orthopaedic Association; MSCC = maximum spinal cord compression; $\mathrm{NAA} / \mathrm{Cr}=\mathrm{N}$-acetylaspartate/creatinine; $\mathrm{OPLL}=$ ossification of the posterior longitudinal ligament; $\mathrm{SCl}=$ spinal cord injury; $\mathrm{SCR}=$ signal change ratio; SSEP = somatosensory evoked potential.

SUBMITTED May 2, 2019. ACCEPTED May 6, 2019.

INCLUDE WHEN CITING DOI: 10.3171/2019.5.SPINE18769. 


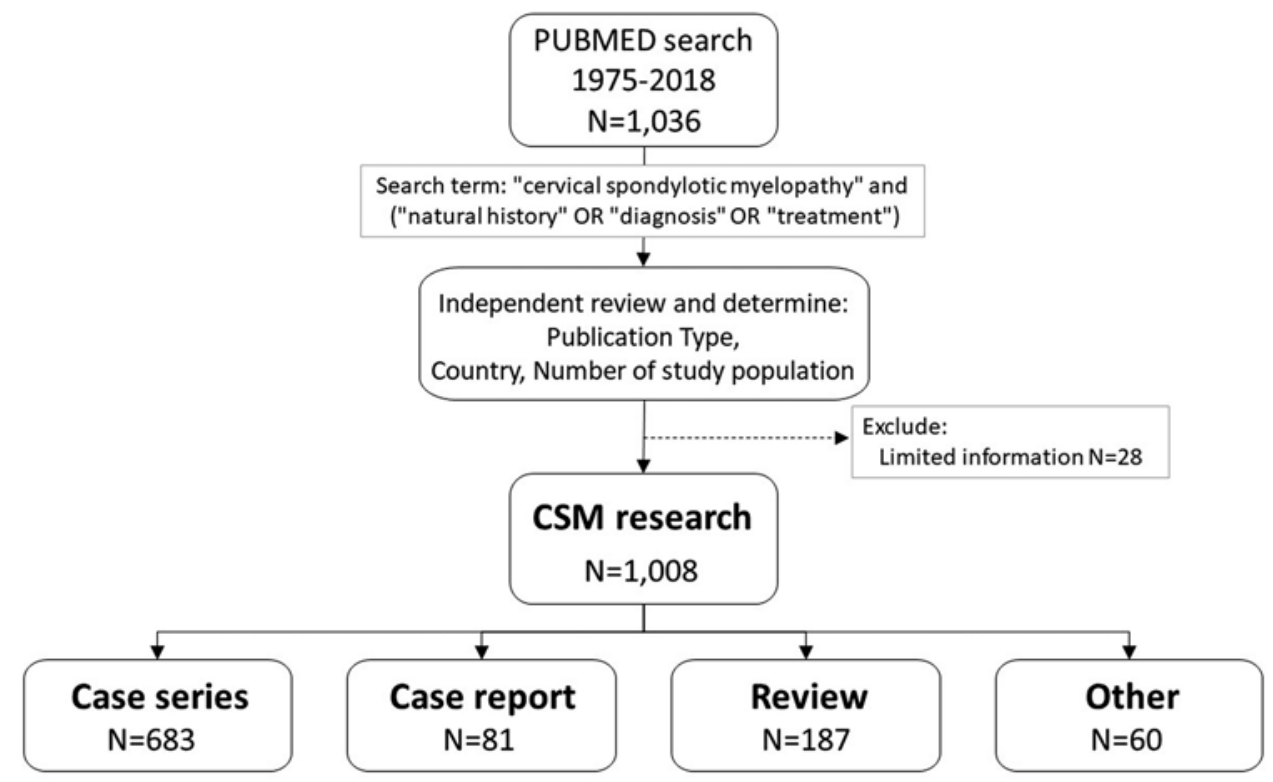

FIG. 1. Data process flow chart of CSM research published between 1975 and $2018(N=1008)$. The total number of the 4 publication types exceeds 1008 because 3 articles were classified into 2 publication types.

facet arthropathies, and ossification of the posterior longitudinal ligament (OPLL) that cause compression of the cervical spinal cord or instability of the vertebrae. ${ }^{25,67}$ Due to the benign nature and insidious development of CSM, it had been less recognized until advanced medical technologies such as MRI and electrophysiological examinations became prevalent in recent decades..$^{47,48,51}$

Currently there are few strategies to rejuvenate the process of degeneration or reverse the spondylosis. Surgery is the most commonly accepted option for severe CSM that is associated with neurological complications. However, for asymptomatic or mildly symptomatic patients with CSM, the optimal management remains controversial. Although great strides have been made in spine surgery in the past decades, including minimally invasive approaches and motion preservation technologies, the exact timing and surgical strategy to treat CSM have remained elusive.

This paper summarizes the currently available literature on CSM, based on a thorough review of journal publications since 1975, with an additional bibliometric analysis of the papers reviewed. The summary aimed to analyze the current trends of research on CSM and to shed light on recent advances in surgical techniques for the treatment of CSM.

\section{Methods}

A literature search using the keywords "cervical spondylotic myelopathy" with "natural history," "diagnosis," or "treatment," and exclusively limited to "human" studies was performed in the PubMed database. The literature search was also limited to articles that were published from January 1, 1975, until January 1, 2019 (a span of 44 years). All articles were downloaded, if possible, and then categorized, and independently reviewed by C.H.K. and C.M.C. The papers were categorized into 4 types of publications: review, case report, case series, and others.
The review category included both literature reviews and systematic reviews. Case reports were defined as reports that had low case numbers and no statistics. Case series included retrospective, cohort, and prospective studies that at least contained statistical analysis. Any other types of papers, including technical notes, editorial summaries, and letters were all categorized as "others" (Fig. 1).

To evaluate the research activity, the doubling time of annual cumulative publication was calculated. The affiliations and countries of the authors of the papers on CSM were all analyzed. The country of origin of each paper was designated using the first author's first affiliation. The abstract of each of the case reports and case series was read and the number of participants in each study population was noted. We excluded papers in which the number in the study population was not identified in the abstract. The citation count of each paper was obtained from the Web of Science (Clarivate Analytics).

To analyze the evolution of surgical strategies for CSM, all the papers regarding treatment were divided into 4 categories: anterior; posterior; combined anterior and posterior; and comparison of anterior versus posterior surgery. This was determined by first using the abstract. If the abstract did not declare the surgical approach, the full text was reviewed. If the surgical approach remained unknown or there was no full text available for review, the paper was then excluded from further analysis.

\section{Results}

A total of 1008 papers dealing with CSM published between 1975 and 2018 were extracted from PubMed and analyzed. The case series category was the most commonly published one, followed by case reports, reviews, and then others. Overall, there was an exponential growth of the number of publications on CSM, with a doubling time of publication at 4.79 years. The review articles category 


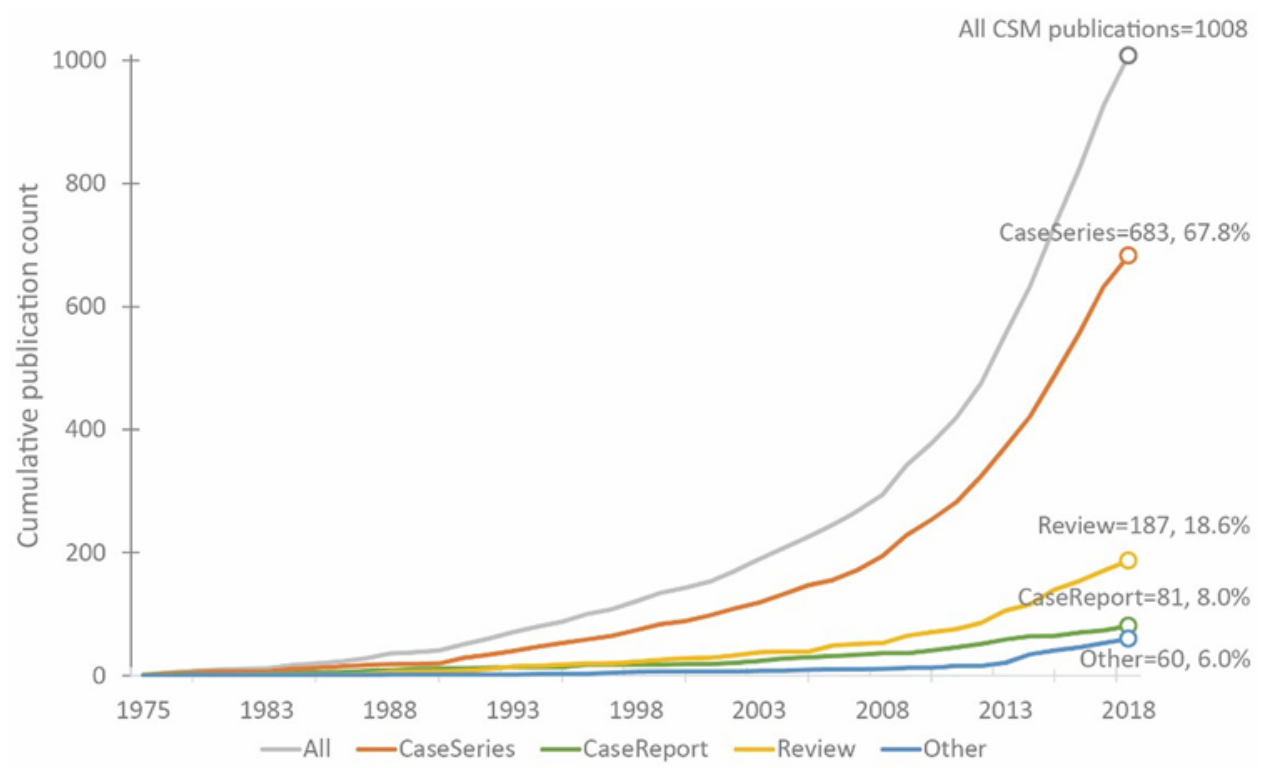

FIG. 2. Cumulative publication counts by publication year and publication types on CSM research published between 1975 and $2018(\mathrm{~N}=1008)$. Figure is available in color online only.

was the second most common, according to the number published (18.6\%) and the rapidity (with a doubling time at 4.57 years). The categories of case reports and others were relatively less common and slower in the rapidity of publication (doubling times at 6.78 and 6.60 years, respectively) (Fig. 2).

The majority of the papers were published in only a few countries. According to an analysis of the countries in which the papers were authored, there were 819 papers (81.3\%) published in 10 countries, of which $50 \%$ of the studies were from Eastern Asia (Table 1). The rate of publication was different by country, and the top 5 countries with the most rapid rate of publication were Korea, China, Japan, India, the US, and Canada (the US and Canada were tied for fifth place). The top 3 countries with growth in the number of papers published were the US, Japan, and China. The types of publications were also different by the countries of publication. There were slightly fewer case reports published by authors based in Asian countries, and there were more review articles published by authors based in the US and Canada than for the other categories (Table 2). There was emerging enthusiasm for research on CSM worldwide, with more publications originating in Asian countries during recent decades (Fig. 3).

There has also been an emerging trend of using large databases for CSM-related research. In most of the case series from single institutions, the study population usually did not exceed 2000. In contrast, CSM research articles using large databases usually were composed of a sample size ranging from several thousand to several million. Furthermore, there has been a trend toward more studies based on larger databases being published in recent years (Fig. 4). There were 18 studies on CSM that used large databases and included more than 2000 patients with CSM as the study population (Appendix Table).

A total of 707 articles on surgical treatment for CSM were analyzed. The papers on surgical treatment were categorized into 4 types according to the surgical ap-

TABLE 1. Cumulative publication counts and publication doubling time of CSM research by countries

\begin{tabular}{|c|c|c|c|c|c|c|c|c|c|c|c|}
\hline $\begin{array}{c}\text { Cumulative } \\
\text { Publication Yrs }\end{array}$ & US & Japan & China* & Canada & India & UK & Korea & Germany & Italy & Taiwan & Others $†$ \\
\hline 1975-1988 & 6 & 0 & 0 & 0 & 0 & 0 & 0 & 0 & 1 & 0 & 29 \\
\hline 1989-1998 & 37 & 21 & 2 & 2 & 1 & 7 & 0 & 3 & 6 & 2 & 40 \\
\hline 1999-2008 & 89 & 77 & 9 & 4 & 8 & 13 & 2 & 4 & 11 & 5 & 72 \\
\hline 2009-2018 & 254 & 188 & 171 & 58 & 34 & 30 & 26 & 21 & 20 & 17 & 189 \\
\hline $\begin{array}{l}\text { Publication doubling } \\
\text { time (yrs) } \ddagger\end{array}$ & 4.44 & 3.71 & 3.51 & 4.44 & 4.13 & 5.91 & 3.40 & 5.01 & 6.94 & 5.38 & 5.69 \\
\hline $\begin{array}{l}\text { Publications between } 19 \\
\text { * Publications originating } \\
\text { † Publications that could } \\
\ddagger \text { Doubling time refers to } \\
\text { active the research in ter }\end{array}$ & t be & $\begin{array}{l}(\mathrm{N}= \\
\text { Kong } \\
\text { gnize } \\
\text { ed tim } \\
\text { ation }\end{array}$ & $\begin{array}{l}\text { not incl } \\
\text { PubMed } \\
\text { the cum }\end{array}$ & $\begin{array}{l}\text { ed until } \\
\text { ata were } \\
\text { ative pub }\end{array}$ & sifie & $\begin{array}{l}\text { hina } \\
\text { Dthe } \\
\text { to d }\end{array}$ & 97. & . & no & - & more \\
\hline
\end{tabular}


TABLE 2. Publication counts of CSM research by countries and publication types

\begin{tabular}{|c|c|c|c|c|c|c|c|c|c|}
\hline \multirow[b]{2}{*}{ Country } & \multicolumn{2}{|c|}{ Case Series } & \multicolumn{2}{|c|}{ Review } & \multicolumn{2}{|c|}{ Case Report } & \multicolumn{2}{|c|}{ Other } & \multirow[b]{2}{*}{ Total } \\
\hline & No. & $\%$ & No. & $\%$ & No. & $\%$ & No. & $\%$ & \\
\hline Overall & 683 & 67.8 & 187 & 18.6 & 81 & 8.0 & 60 & 6.0 & 1008 \\
\hline US & 123 & 48.0 & 90 & 35.2 & 28 & 10.9 & 15 & 5.9 & 256 \\
\hline Japan & 154 & 81.9 & 9 & 4.8 & 17 & 9.0 & 8 & 4.3 & 188 \\
\hline China & 132 & 76.7 & 26 & 15.1 & 8 & 4.7 & 6 & 3.5 & 172 \\
\hline Canada & 25 & 43.1 & 25 & 43.1 & & & 8 & 13.8 & 58 \\
\hline India & 30 & 88.2 & 1 & 2.9 & 2 & 5.9 & 1 & 2.9 & 34 \\
\hline UK & 19 & 63.3 & 3 & 10.0 & 5 & 16.7 & 3 & 10.0 & 30 \\
\hline Korea & 23 & 88.5 & 1 & 3.8 & 1 & 3.8 & 1 & 3.8 & 26 \\
\hline Germany & 13 & 61.9 & 2 & 9.5 & 1 & 4.8 & 5 & 23.8 & 21 \\
\hline Italy & 15 & 75.0 & 2 & 10.0 & 1 & 5.0 & 2 & 10.0 & 20 \\
\hline Taiwan & 16 & 94.1 & & & & & 1 & 5.9 & 17 \\
\hline Others & 133 & 70.4 & 28 & 14.8 & 18 & 9.5 & 10 & 5.3 & 189 \\
\hline
\end{tabular}

Publications between 1975 and $2018(\mathrm{~N}=1011)$. The total number in the 4 publication types exceeds 1008 because 3 articles were classified into 2 publication types.

proaches: anterior (291, 41.2\%); posterior $(274,38.8 \%)$; combined anterior and posterior $(82,11.6 \%)$; and only a few $(60,5.4 \%)$ that compared the anterior versus posterior surgery. The publication of surgical series had an exponential growth in recent decades. Moreover, the volume of research on anterior and posterior approaches had no discrepancies until the last decade. Anterior surgery has been reported more and has trended higher than posterior surgery since then (Fig. 5).

\section{Discussion}

\section{Summary of Featured Articles}

In-depth reviews were performed for articles describing human studies, focusing on the natural history, pathophysiology, and diagnosis and treatment of mild CSM.

\section{Natural History and Pathophysiology of CSM}

Most of the reports on CSM indicated a decline in patients' neurological status, including hand dexterity, gait disturbance, and sphincter functions. However, the patterns of deterioration could vary, from a rapid onset of symptoms followed by long periods of remission, to a slow and gradual decline or a stepwise decline. The speed of the decline could depend on the related pathologies, the cause of onset, timing of the diagnoses, and simply the duration of observation.

There was an increased risk of spinal cord injury (SCI) in patients with CSM. In an East Asian cohort study of 14,140 patients hospitalized for CSM, the overall incidence of CSM-related hospitalization was 40.4 per million person-years, with male and elderly patients predominant. ${ }^{70}$ Subsequent SCI was more likely to develop in those CSM patients who received nonoperative management than in those who underwent surgery. Furthermore, in an even larger cohort from the same region, patients with CSM had an overall incidence rate of SCI at approximately $0.2 \%$ per year. ${ }^{12}$ Because male sex, the coexistence of OPLL, and nonoperative management are twice as likely to be associated with subsequent SCI, surgery is therefore suggested for these patients with CSM, especially for those who are at higher risk..$^{12,68,70,71}$

The main components contributing to the cervical cord compression and subsequent CSM could be classified into static and dynamic factors. The structural spondylotic abnormalities causing spinal stenosis and subsequent cord compression were referred to as the static factors. Disc degeneration would be the initiating event of these spondylotic cascades. Cervical spine biomechanics could be changed by disc degeneration causing ligamentum flavum hypertrophy as well as laxity of the facet joint, progressive biomechanical stress, and strain on the spinal joints..$^{32}$ Thus, unfused spinal levels adjacent to congenital and iatrogenic fusions may have early disc degeneration and accelerate spondylosis. In a study of 22 patients with Klippel-Feil syndrome who had a mean age of 35 years, disc degeneration with evidence of low-intensity signal on T2weighted MRI was observed in all patients, in addition to other abnormal findings such as disc protrusion, formation of osteophytes, and syringomyelia. ${ }^{24}$ There were also studies addressing OPLL, which had higher incidences in Japan, Taiwan, and other East Asian countries, as another causative factor in the pathophysiology of CSM.67 The incidence of cervical OPLL-related hospitalization for patients with severe CSM in a national cohort from Taiwan was as high as 6.1 per million person-years, with the higher rates observed in the elderly and among male patients. $^{71}$

A congenitally narrow spinal canal was also regarded as a potential risk for CSM. In a prospective study including 295 patients, individuals were classified into 3 groups according to the sagittal cervical spinal canal diameter (group A: less than $13 \mathrm{~mm}$, group B: $13-15 \mathrm{~mm}$, and group C: more than $15 \mathrm{~mm}$ ). Group A patients were observed to have a higher risk of pathological changes in cervical intervertebral discs, which could lead individuals to have a greater risk of developing cervical spinal ste- 

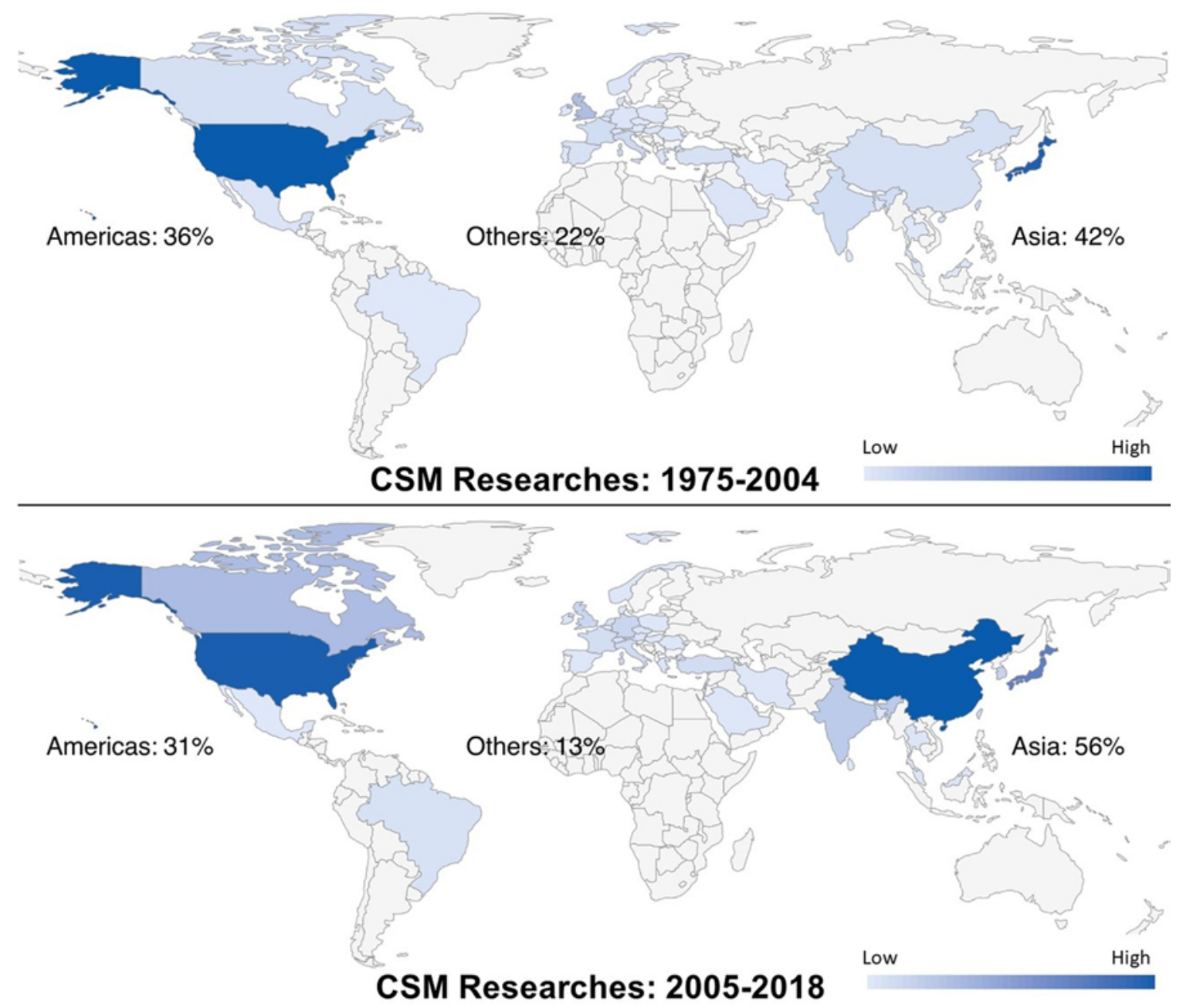

FIG. 3. Global maps demonstrating the distribution of CSM-related researches before and after 2005. Maps created with datamaps.co@. Figure is available in color online only.

nosis subsequently. ${ }^{44}$ Similar findings also were observed in autopsy studies. The pathological progression appeared to worsen with duration of compression and severity of anterior-posterior compression, which means the diameter of the spinal canal..$^{30,50}$ A narrowed spinal canal may be associated with poor vascularity, but there were no reports in humans to document ischemia as a contributing factor to the development of CSM.

Dynamic factors for CSM referred to repetitive injury during the flexion or extension movements of the cervical spine on the compressed cervical spinal cord..$^{32}$ The repetitive chronic subtle SCI could be exaggerated in cases of instability. The "wear and tear change" of cervical spondylosis might be correlated to the repetitively forcible neck flexion and extension that caused early development of osteophytes, but this was never demonstrated in a human study. In a human study including 47 rugby players and 40 age-matched control subjects, early cervical degeneration was detected more often on MR scans in the front-line rugby players than in the control subjects of the same age, which may be correlated with repetitive cervical trauma throughout the players' careers. ${ }^{4}$ Also, there have been concerns about the potential risk of cervical SCI in professional wrestlers and others who play contact sports. ${ }^{54}$

\section{Diagnosis of CSM}

Diagnosis of CSM could be established using clinical examinations, radiological studies, or electrophysiological evaluations. There was a prospective multicenter study that included 114 patients in which researchers attempted to correlate the preoperative clinical presentations to quantitative features by using MRI. They addressed several MRI features, including the maximum spinal cord compression (MSCC), maximum canal compromise (MCC), signal changes, and a signal change ratio (SCR). The paper demonstrated associations among upper-limb symptoms and MSCC, and neurological deficits over all 4 extremities and SCR. Some results of typical neurological examinations for patients with CSM also had significant correlation with MRI features. For instance, the Hoffmann sign was more commonly observed in patients with a greater MSCC, MCC, and SCR, whereas the Lhermitte 


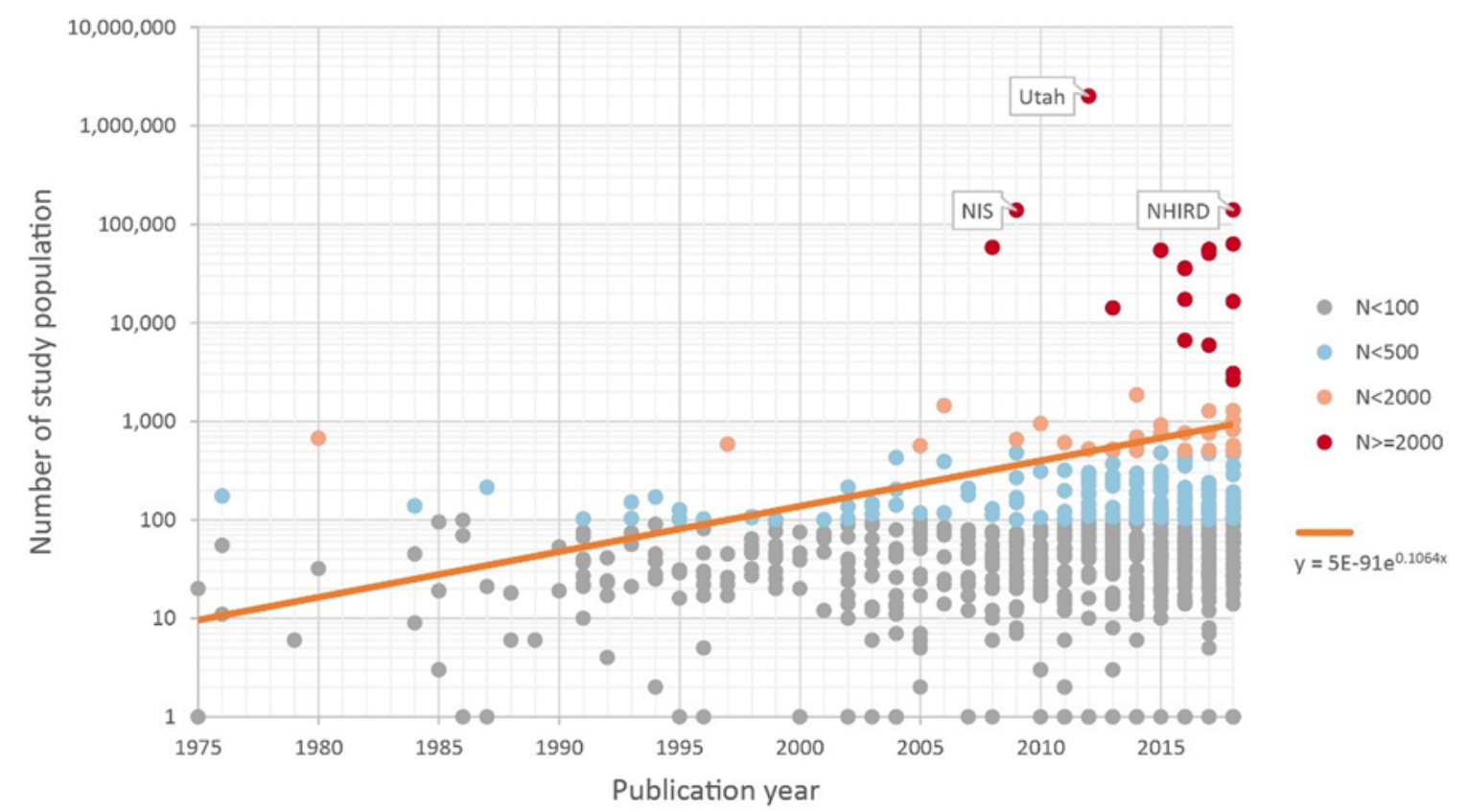

FIG. 4. Scatter plot of numbers of each study population of CSM research, focusing on treatment by publication year $(n=764$, 1975-2018). Each dot represents 1 CSM paper. The different colors denote the number of each study population. Orange line: a fitted trend line to display the relationship between publication year and the average of number of study population, which suggested a 1.11-fold exponential increase per year. NHIRD = National Health Insurance Research Database; NIS = National (Nationwide) Inpatient Sample. Figure is available in color online only.

phenomenon presented more commonly in patients with a lower SCR, which has the potential to be an early indicator for early-stage CSM. ${ }^{48}$

Abnormalities of intramedullary signal intensity on MRI have been regarded as a convenient clinical predictor for patients with CSM. The hyperintense signals within the spinal cord parenchyma demonstrated on T2weighted MRI have been proven to correlate with myelopathy. $7,23,25,33,58,63$ In a study that enrolled 57 patients with CSM, pre- and postoperative MRI studies with clinical data regarding the Nurick grade were collected. As most spine surgeons would expect, the results demonstrated that a preoperative focal T2 hyperintensity signal had a significant association with a lower Nurick grade preand postoperatively. ${ }^{2}$ Moreover, the modified Japanese Orthopaedic Association (mJOA) score was regarded as a strong predictor of the surgical outcomes of CSM. In a study of 102 patients whose pre- and postoperative clinical and MRI data were analyzed, the authors concluded that baseline mJOA was a strong predictor of postsurgical outcomes in CSM. ${ }^{49,63}$

Electrophysiological evaluations, including somatosensory evoked potentials (SSEPs) and motor evoked potentials (MEPs), nerve conduction studies, and EMG, were useful tools to identify injury to the neural elements. ${ }^{47,60}$ Longer duration, higher amplitude, and polyphasic motor units could be observed on EMG examination when there was anterior cord compression, damage of anterior horn cells, or compression of the motor nerve roots at a particular level. A nerve conduction study could be applied to differentiate other etiologies, such as peripheral neuropathies caused by trauma or metabolic disorders..$^{60}$ For the patients with radiologically detected cervical spondylosis without confirmative symptoms or pyramidal signs, frequently abnormal MEPs or SSEPs can be observed, and the sensitivity of MEPs might be superior to SSEPs in detecting CSM in the early stages..$^{55}$

A few other MRI techniques have been used for the evaluation of patients with mild CSM. ${ }^{34}$ There was a prospective study that included 60 patients with mild CSM, in which the spinal cord shapes on MRI were classified as ovoid deformity (both sides were convex and round) or angular-edged deformity (both sides exhibited an acuteangled lateral corner) according to the axial T1-weighted MRI. These patients were enrolled between 1995 and 2003 and followed up periodically until the date of myelopathy deterioration or until 2009. The authors suggested that patients with the ovoid type had a better prognosis, with a tolerance rate of $70 \%$ (little or slight deterioration) without surgical treatment, versus 58\% for the cases with angular-edged deformity. Therefore, the investigators concluded that surgical intervention should be considered for patients with mild CSM and angular-edged deformity on axial MRI examination. .5

Furthermore, kinetic MRI was applied to early detection of nonobvious lesions in patients with mild CSM. The cervical MRI performed in flexion/extension positions was able to reveal the narrowest part of the compressionaffected level for the early diagnosis of CSM ${ }^{57}$ Diffusion tensor imaging has been applied as an imaging biomarker to evaluate the microstructural integrity in patients with CSM. In a series of 48 patients, among whom mJOA scores were evaluated clinically, diffusion tensor imaging was correlated with neurological impairment. ${ }^{16}$ MR spec- 


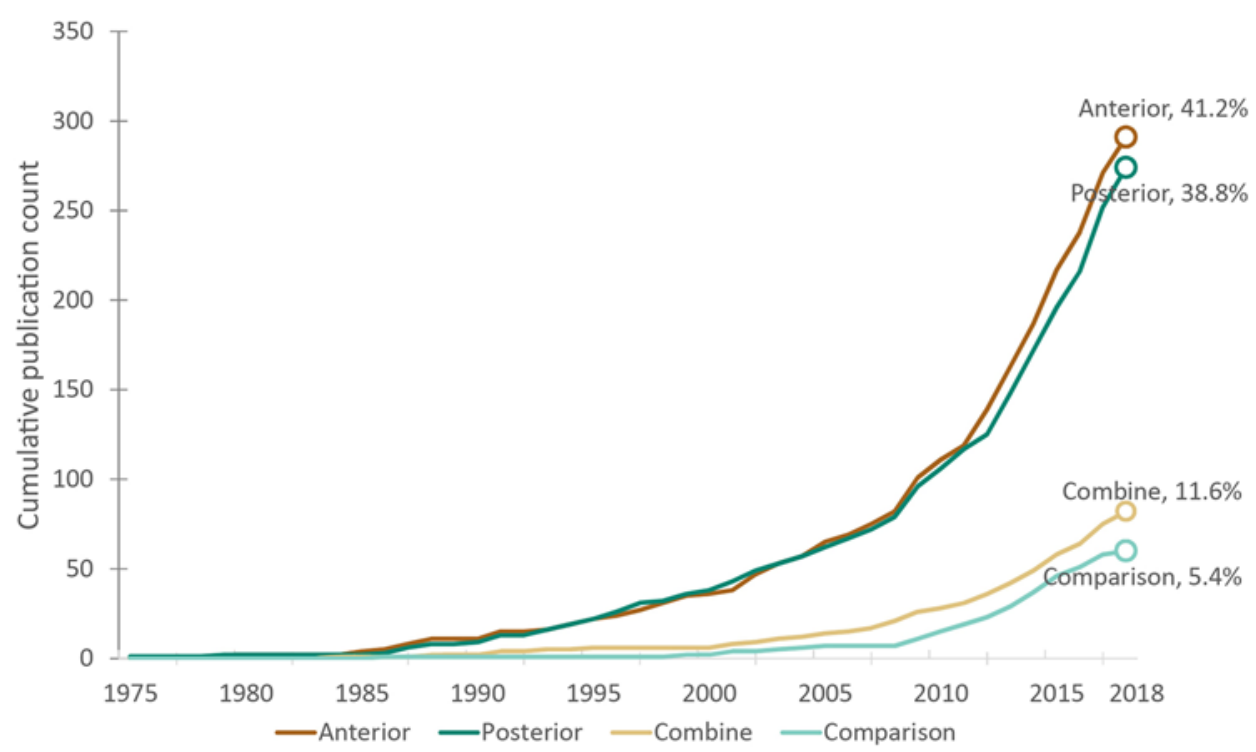

FIG. 5. Cumulative publication counts by publication year and surgical approaches on CSM research published between 1975 and $2018(n=707)$. Figure is available in color online only.

troscopy over the primary motor cortex was also used as a predictor for the severity of CSM. In a series of 28 patients who were classified as having a mild to moderate degree of CSM according to their mJOA scores, a lower preoperative $\mathrm{N}$-acetylaspartate/creatinine (NAA/Cr) ratio was observed in the patients with mild CSM, compared to those with moderate severity. Interestingly, after surgical intervention, the NAA/Cr ratio in the patients with moderate severity improved to the same level as those who had only mild CSM. Therefore, the NAA/Cr ratio measured on MR spectroscopy could be used to determine the severity of the disease in patients with CSM and also applied to evaluate the outcomes after surgery. ${ }^{1}$

\section{Treatment for CSM}

Most clinicians would agree that surgery benefits patients with severe CSM who have marked symptoms and neurological deficits. However, the clinical prognosis of patients with mild CSM remained uncertain, and the rate of worsening was not easily predictable. Therefore, the best timing for conversion of nonoperative management to surgical intervention is still being debated. It is weighed among several factors regarding the patient, disease, and surgeon. There was no prospective randomized controlled trial on the issue. However, there was a retrospective study that included 45 patients with mild CSM with a mean follow-up of more than 6 years; the clinical course was observed under nonoperative management until the end point at which was set the conversion to surgery due to neurological deterioration. In the series, $56 \%$ of patients had no neurological deterioration and did not undergo surgery during 10 years of follow-up, whereas a large range of motion, segmental kyphosis, and instability at the narrowest part of the canal were considered prognostic factors for adverse outcomes. ${ }^{51}$ In a 3-year randomized prospective study published in 2005 in which nonoperative and operative management of CSM were compared, the patients with a good outcome in the conservatively treated group were older before treatment, had normal central motor conduction time, and possessed a larger transverse area $\left(>70 \mathrm{~mm}^{2}\right)$ of the spinal cord. ${ }^{31}$ In other words, surgery was definitely needed in patients with CSM who had clinically worse presentation and remarkable spinal stenosis. ${ }^{40}$ Surgical intervention is usually favorable for CSM caused by definite factors such as disc herniation, OPLL, and age-related degeneration. ${ }^{46}$ For the patients with mild symptoms who had evident intramedullary signal intensity change on MRI, the clinical outcome between surgery and nonoperative treatment during the short-term followup was not significantly different. ${ }^{39}$ However, there has not been enough evidence for the prognosis of mild CSM that was treated nonoperatively. Surgical intervention is definitely warranted for patients with progressive deterioration of neurological functions. ${ }^{46,59}$

Static and/or dynamic spinal cord compression resulting from spondylosis could eventually lead to CSM. Advances in diagnostic technology, including various imaging modalities, combined with surgical intervention, including decompression and stabilization, could improve the patients' neurological functions, related disability, clinical outcomes, and quality of life. ${ }^{21,36,37,41,45}$ The ideal surgical strategies should be tailored by the characteristics and location of cord compression..$^{38}$ The main purpose of surgery is usually to decompress the spinal cord while stabilizing the affected segments, and sometimes to prevent or cease progression of kyphotic deformity in the future..$^{1,15,64}$ Spinal cord decompression can be performed via anterior, posterior, or combined approaches, which has been a classic topic of debate in spine surgery. Anterior surgery has included discectomy and corpectomy with or without instrumentation, whereas posterior options have included laminoplasty and laminectomy with or without instrumentation. ${ }^{53}$ Since its invention in 1958, anterior cervical 


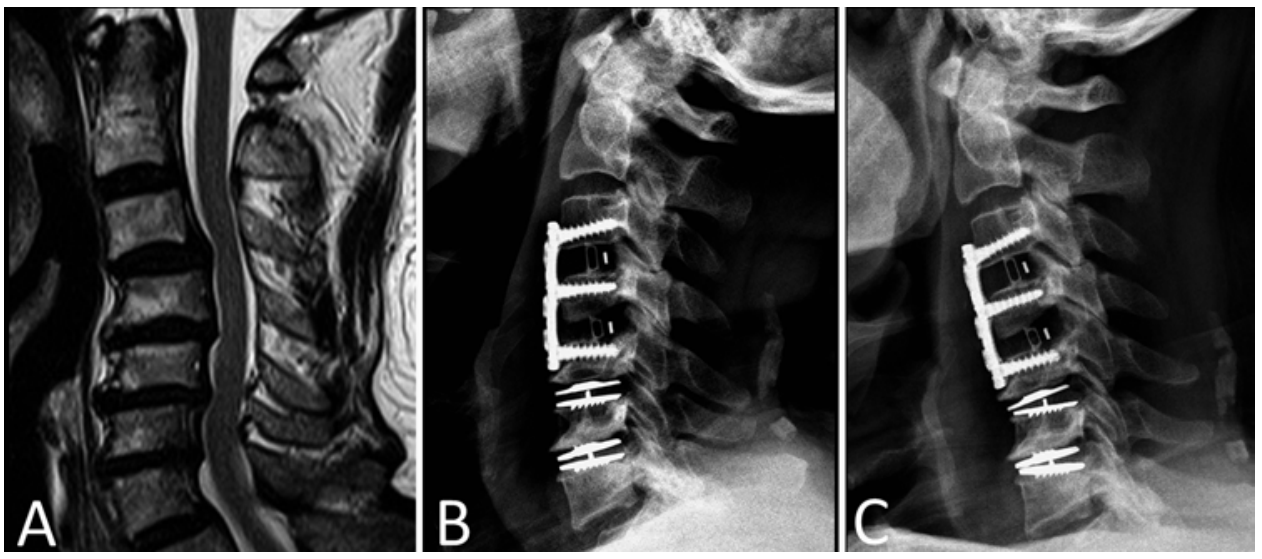

FIG. 6. Illustrative case. A 69-year-old man who presented with bilateral hand numbness and lower-limb weakness for months. The MR images demonstrated C3-7 multilevel spondylotic myelopathy with mild kyphotic deformity (A). The patient had tried physical therapy and other nonoperative management, which gave little improvement. Therefore, he underwent anterior hybrid surgery: ACDF at C3-4-5 and CDA at C5-6-7. There was significant improvement in clinical outcome, and the lateral dynamic cervical radiographs (B, flexion; $\mathbf{C}$, extension) demonstrated partial correction of the kyphosis and preservation of segmental mobility.

discectomy and fusion (ACDF) has fast become a standard option of surgical management for CSM, degenerative disc disease, and kyphosis. ${ }^{13,17}$ The application of instrumentation and plate fixation in ACDF could mitigate the risk of cage dislodgement and pseudarthrosis. ${ }^{3,29,65}$ Furthermore, with the application of modern grafting techniques and biologics, ACDF yields extremely high success rates and patient satisfaction. ${ }^{42,43,54,61,72}$ In a meta-analysis that included 878 patients with CSM caused by multilevel disease, anterior cervical fusion procedures, including both ACDF and anterior cervical discectomy and corpectomy with fusion (ACCF), were valid strategies for good clinical outcomes. However, the results revealed that ACDF was even more effective than ACCF in $\mathrm{C} 2-7$ lordotic angle correction, without differences in length of hospital stay, functional outcomes, and rates of complications.

There has been increasing popularity of cervical disc arthroplasty (CDA) since 2000. Although the outcomes of ACDF have been extraordinarily good, it still has drawbacks: there has been a potential risk of inducing iatrogenic CSM over the adjacent levels of fusions. ${ }^{28}$ Therefore, the emerging technology of CDA has offered an alternative option of preservation of disc mobility, which stabilizes the spine after discectomy. It has been widely accepted for years that CDA provided equal therapeutic outcome with arthrodesis for patients with single-level cervical myelopathy. There were also prospective multicenter randomized controlled trials on many devices used in CDA, with up to 7 years of results published, demonstrating equal efficacy in management of 1- and 2-level disc herniations that caused radiculopathy and myelopathy. ${ }^{8,14,52,62}$ Moreover, there has been a growing body of literature addressing the outcomes of CDA in CSM, including congenital stenosis. ${ }^{9-11,18,19,66,69}$ The use of CDA in patients with CSM might reduce the chance of adjacent segment degeneration, especially in patients with multilevel disc diseases. ${ }^{18,19}$ Although the true effect of preservation of segmental mobility on the natural course of CSM remains uncertain, no adverse clinical outcomes have been reported. Given the potential advantage of deceleration in adjacent segment degeneration, the technology of CDA could benefit patients with CSM caused by multilevel disc herniations and spondylosis (Fig. 6).

Posterior cervical surgery, including laminoplasty and laminectomy with or without instrumentation, also serves as a viable option to treat CSM. There were numerous publications that addressed various technical modifications, improved outcomes, and consequences of posterior cervical laminoplasty. ${ }^{22,27,37}$ In a prospective study in which 169 patients with anterior and 95 patients with posterior surgery were compared, there were no differences in significant clinical improvements and adverse effects. ${ }^{20}$ However, in that particular study for multilevel CSM, the anterior approaches were associated with higher rates of complications and reoperations than the posterior approaches. There was another study that investigated the efficacy of posterior laminoplasty in 80 patients with a mean followup of 47 months; it demonstrated substantial postoperative clinical improvement, and the postoperative MRI also indicated a tremendous increase in the diameter of spinal canals after surgery. ${ }^{5}$

On the other hand, the issue regarding posterior shifting of the spinal cord after posterior laminectomy has drawn attention and has been considered factorial in causing neurological deterioration, such as $\mathrm{C} 5$ palsy. ${ }^{35} \mathrm{~A}$ retrospective study of 51 patients with multilevel CSM divided patients into 2 groups: selective laminoplasty and bilateral opendoor laminoplasty. Although the latter group had more cord shifting than in the selective laminoplasty group, the incidences of C5 palsy were not different, and there was no correlation between the recovery rate and the magnitude of posterior shifting of the spinal cord. ${ }^{26}$ Most spine surgeons would agree that preoperative kyphotic deformity should preclude laminoplasty and should prompt the surgeons to consider correction and fusion. ${ }^{6}$ A matched cohort study that included 101 patients who underwent laminoplasty and 44 who received laminectomy with posterior fusion for treatment of CSM demonstrated that laminectomy with posterior fusion had greater blood loss and higher rates of 
long-term complications. Nevertheless, laminectomy and fusion provided better neurological improvement than the group treated with laminoplasty, but the outcomes for pain control showed no differences between the 2 groups. Among the patients who underwent laminoplasty, there was a trend toward greater cervical lordosis, which was also associated with lower incidences of poor visual analog scale scores. Cervical lordosis should thus be considered an important factor of pain control, especially following posterior approaches to multilevel CSM. ${ }^{37}$

\section{Conclusions}

There is emerging enthusiasm for research on CSM worldwide, with more publications originating in Asian countries during the past several decades. The surgical management for CSM is evolving continuously toward early and anterior approaches. More prospective investigations on the optimal timing and choices of surgery are therefore needed.

\section{References}

1. Aleksanderek I, Stevens TK, Goncalves S, Bartha R, Duggal $\mathrm{N}$ : Metabolite and functional profile of patients with cervical spondylotic myelopathy. J Neurosurg Spine 26:547-553, 2017

2. Arvin B, Kalsi-Ryan S, Mercier D, Furlan JC, Massicotte EM, Fehlings MG: Preoperative magnetic resonance imaging is associated with baseline neurological status and can predict postoperative recovery in patients with cervical spondylotic myelopathy. Spine (Phila Pa 1976) 38:1170-1176, 2013

3. Barnes B, Haid RW, Rodts GE, Subach BR, Kaiser M: Early results using the Atlantis anterior cervical plate system. Neurosurg Focus 12(1):E13, 2002

4. Berge J, Marque B, Vital JM, Sénégas J, Caillé JM: Agerelated changes in the cervical spines of front-line rugby players. Am J Sports Med 27:422-429, 1999

5. Bhatia NN, Lopez G, Geck M, Gottlieb J, Eismont F: Posterior cervical laminoplasty in the North American population: a minimum of two year follow-up. Clin Neurol Neurosurg 138:165-168, 2015

6. Cao J, Zhang J, Yang D, Yang L, Shen Y: Multivariate analysis of factors associated with kyphotic deformity after laminoplasty in cervical spondylotic myelopathy patients without preoperative kyphotic alignment. Sci Rep 7:43443, 2017

7. Cao JM, Zhang JT, Yang DL, Yang YP, Xia HH, Yang L: Imaging factors that distinguish between patients with asymptomatic and symptomatic cervical spondylotic myelopathy with mild to moderate cervical spinal cord compression. Med Sci Monit 23:4901-4908, 2017

8. Chang CC, Huang WC, Wu JC, Mummaneni PV: The option of motion preservation in cervical spondylosis: cervical disc arthroplasty update. Neurospine 15:296-305, 2018

9. Chang HC, Tu TH, Chang HK, Wu JC, Fay LY, Chang PY, et al: Hybrid corpectomy and disc arthroplasty for cervical spondylotic myelopathy caused by ossification of posterior longitudinal ligament and disc herniation. World Neurosurg 95:22-30, 2016

10. Chang HK, Huang WC, Wu JC, Chang PY, Tu TH, Fay LY, et al: Should cervical disc arthroplasty be done on patients with increased intramedullary signal intensity on magnetic resonance imaging? World Neurosurg 89:489-496, 2016

11. Chang PY, Chang HK, Wu JC, Huang WC, Fay LY, Tu TH, et al: Is cervical disc arthroplasty good for congenital cervical stenosis? J Neurosurg Spine 26:577-585, 2017

12. Chen LF, Tu TH, Chen YC, Wu JC, Chang PY, Liu L, et al:
Risk of spinal cord injury in patients with cervical spondylotic myelopathy and ossification of posterior longitudinal ligament: a national cohort study. Neurosurg Focus 40(6):E4, 2016

13. Cloward RB: The anterior approach for removal of ruptured cervical disks. J Neurosurg 15:602-617, 1958

14. Coric D, Guyer RD, Nunley PD, Musante D, Carmody C, Gordon C, et al: Prospective, randomized multicenter study of cervical arthroplasty versus anterior cervical discectomy and fusion: 5-year results with a metal-on-metal artificial disc. J Neurosurg Spine 28:252-261, 2018

15. Craciunas SC, Gorgan MR, Ianosi B, Lee P, Burris J, Cirstea $\mathrm{CM}$ : Remote motor system metabolic profile and surgery outcome in cervical spondylotic myelopathy. J Neurosurg Spine 26:668-678, 2017

16. Ellingson BM, Salamon N, Grinstead JW, Holly LT: Diffusion tensor imaging predicts functional impairment in mild-to-moderate cervical spondylotic myelopathy. Spine J 14:2589-2597, 2014

17. Emery SE, Bohlman HH, Bolesta MJ, Jones PK: Anterior cervical decompression and arthrodesis for the treatment of cervical spondylotic myelopathy. Two to seventeen-year follow-up. J Bone Joint Surg Am 80:941-951, 1998

18. Fay LY, Huang WC, Tsai TY, Wu JC, Ko CC, Tu TH, et al: Differences between arthroplasty and anterior cervical fusion in two-level cervical degenerative disc disease. Eur Spine J 23:627-634, 2014

19. Fay LY, Huang WC, Wu JC, Chang HK, Tsai TY, Ko CC, et al: Arthroplasty for cervical spondylotic myelopathy: similar results to patients with only radiculopathy at 3 years' followup. J Neurosurg Spine 21:400-410, 2014

20. Fehlings MG, Barry S, Kopjar B, Yoon ST, Arnold P, Massicotte EM, et al: Anterior versus posterior surgical approaches to treat cervical spondylotic myelopathy: outcomes of the prospective multicenter AOSpine North America CSM study in 264 patients. Spine (Phila Pa 1976) 38:2247-2252, 2013

21. Fehlings MG, Wilson JR, Kopjar B, Yoon ST, Arnold PM, Massicotte EM, et al: Efficacy and safety of surgical decompression in patients with cervical spondylotic myelopathy: results of the AOSpine North America prospective multicenter study. J Bone Joint Surg Am 95:1651-1658, 2013

22. Gandhoke G, Wu JC, Rowland NC, Meyer SA, Gupta C, Mummaneni PV: Anterior corpectomy versus posterior laminoplasty: is the risk of postoperative C-5 palsy different? Neurosurg Focus 31(4):E12, 2011

23. Guan X, Fan G, Wu X, Gu G, Gu X, Zhang H, et al: Diffusion tensor imaging studies of cervical spondylotic myelopathy: a systemic review and meta-analysis. PLoS One 10:e0117707, 2015

24. Guille JT, Miller A, Bowen JR, Forlin E, Caro PA: The natural history of Klippel-Feil syndrome: clinical, roentgenographic, and magnetic resonance imaging findings at adulthood. J Pediatr Orthop 15:617-626, 1995

25. Harrop JS, Naroji S, Maltenfort M, Anderson DG, Albert T, Ratliff JK, et al: Cervical myelopathy: a clinical and radiographic evaluation and correlation to cervical spondylotic myelopathy. Spine (Phila Pa 1976) 35:620-624, 2010

26. Hatta Y, Shiraishi T, Hase H, Yato Y, Ueda S, Mikami Y, et al: Is posterior spinal cord shifting by extensive posterior decompression clinically significant for multisegmental cervical spondylotic myelopathy? Spine (Phila Pa 1976) 30:2414-2419, 2005

27. Highsmith JM, Dhall SS, Haid RW Jr, Rodts GE Jr, Mummaneni PV: Treatment of cervical stenotic myelopathy: a cost and outcome comparison of laminoplasty versus laminectomy and lateral mass fusion. J Neurosurg Spine 14:619-625, 2011

28. Hilibrand AS, Carlson GD, Palumbo MA, Jones PK, Bohlman HH: Radiculopathy and myelopathy at segments adja- 
cent to the site of a previous anterior cervical arthrodesis. J Bone Joint Surg Am 81:519-528, 1999

29. Islam MA, Islam MA, Habib MA, Sakeb N: Anterior cervical discectomy, fusion and stabilization by plate and screw-early experience. Bangladesh Med Res Counc Bull 38:62-66, 2012

30. Ito T, Oyanagi K, Takahashi H, Takahashi HE, Ikuta F: Cervical spondylotic myelopathy. Clinicopathologic study on the progression pattern and thin myelinated fibers of the lesions of seven patients examined during complete autopsy. Spine (Phila Pa 1976) 21:827-833, 1996

31. Kadanka Z, Mares M, Bednarík J, Smrcka V, Krbec M, Chaloupka R, et al: Predictive factors for mild forms of spondylotic cervical myelopathy treated conservatively or surgically. Eur J Neurol 12:16-24, 2005

32. Karadimas SK, Erwin WM, Ely CG, Dettori JR, Fehlings MG: Pathophysiology and natural history of cervical spondylotic myelopathy. Spine (Phila Pa 1976) 38 (22 Suppl 1):S21-S36, 2013

33. Karpova A, Arun R, Kalsi-Ryan S, Massicotte EM, Kopjar B, Fehlings MG: Do quantitative magnetic resonance imaging parameters correlate with the clinical presentation and functional outcomes after surgery in cervical spondylotic myelopathy? A prospective multicenter study. Spine (Phila Pa 1976) 39:1488-1497, 2014

34. Kolcun JP, Chieng LO, Madhavan K, Wang MY: The role of dynamic magnetic resonance imaging in cervical spondylotic myelopathy. Asian Spine J 11:1008-1015, 2017

35. Krätzig T, Mohme M, Mende KC, Eicker SO, Floeth FW: Impact of the surgical strategy on the incidence of $\mathrm{C} 5$ nerve root palsy in decompressive cervical surgery. PLoS One 12: 0188338,2017

36. Lau D, Chou D, Mummaneni PV: Two-level corpectomy versus three-level discectomy for cervical spondylotic myelopathy: a comparison of perioperative, radiographic, and clinical outcomes. J Neurosurg Spine 23:280-289, 2015

37. Lau D, Winkler EA, Than KD, Chou D, Mummaneni PV: Laminoplasty versus laminectomy with posterior spinal fusion for multilevel cervical spondylotic myelopathy: influence of cervical alignment on outcomes. J Neurosurg Spine 27:508-517, 2017

38. Lebl DR, Bono CM: Update on the diagnosis and management of cervical spondylotic myelopathy. J Am Acad Orthop Surg 23:648-660, 2015

39. Li FN, Li ZH, Huang X, Yu SZ, Zhang F, Chen Z, et al: The treatment of mild cervical spondylotic myelopathy with increased signal intensity on T2-weighted magnetic resonance imaging. Spinal Cord 52:348-353, 2014

40. Madhavan K, Chieng LO, Foong H, Wang MY: Surgical outcomes of elderly patients with cervical spondylotic myelopathy: a meta-analysis of studies reporting on 2868 patients. Neurosurg Focus 40(6):E13, 2016

41. Matz PG, Anderson PA, Holly LT, Groff MW, Heary RF, Kaiser MG, et al: The natural history of cervical spondylotic myelopathy. J Neurosurg Spine 11:104-111, 2009

42. Matz PG, Holly LT, Groff MW, Vresilovic EJ, Anderson PA, Heary RF, et al: Indications for anterior cervical decompression for the treatment of cervical degenerative radiculopathy. J Neurosurg Spine 11:174-182, 2009

43. Matz PG, Holly LT, Mummaneni PV, Anderson PA, Groff MW, Heary RF, et al: Anterior cervical surgery for the treatment of cervical degenerative myelopathy. J Neurosurg Spine 11:170-173, 2009

44. Morishita Y, Naito M, Hymanson H, Miyazaki M, Wu G, Wang JC: The relationship between the cervical spinal canal diameter and the pathological changes in the cervical spine. Eur Spine J 18:877-883, 2009

45. Mummaneni PV, Kaiser MG, Matz PG, Anderson PA, Groff MW, Heary RF, et al: Cervical surgical techniques for the treatment of cervical spondylotic myelopathy. J Neurosurg Spine 11:130-141, 2009

46. Naito K, Yamagata T, Ohata K, Takami T: Management of the patient with cervical cord compression but no evidence of myelopathy: what should we do? Neurosurg Clin N Am 29:145-152, 2018

47. Nakai S, Sonoo M, Shimizu T: Somatosensory evoked potentials (SEPs) for the evaluation of cervical spondylotic myelopathy: utility of the onset-latency parameters. Clin Neurophysiol 119:2396-2404, 2008

48. Nouri A, Tetreault L, Dalzell K, Zamorano JJ, Fehlings MG: The relationship between preoperative clinical presentation and quantitative magnetic resonance imaging features in patients with degenerative cervical myelopathy. Neurosurgery 80:121-128, 2017

49. Nouri A, Tetreault L, Zamorano JJ, Dalzell K, Davis AM, Mikulis D, et al: Role of magnetic resonance imaging in predicting surgical outcome in patients with cervical spondylotic myelopathy. Spine (Phila Pa 1976) 40:171-178, 2015

50. Ogino H, Tada K, Okada K, Yonenobu K, Yamamoto T, Ono $\mathrm{K}$, et al: Canal diameter, anteroposterior compression ratio, and spondylotic myelopathy of the cervical spine. Spine (Phila Pa 1976) 8:1-15, 1983

51. Oshima Y, Seichi A, Takeshita K, Chikuda H, Ono T, Baba S, et al: Natural course and prognostic factors in patients with mild cervical spondylotic myelopathy with increased signal intensity on T2-weighted magnetic resonance imaging. Spine (Phila Pa 1976) 37:1909-1913, 2012

52. Radcliff K, Davis RJ, Hisey MS, Nunley PD, Hoffman GA, Jackson RJ, et al: Long-term evaluation of cervical disc arthroplasty with the Mobi-C(C) cervical disc: a randomized, prospective, multicenter clinical trial with seven-year followup. Int J Spine Surg 11:31, 2017

53. Rao RD, Gourab K, David KS: Operative treatment of cervical spondylotic myelopathy. J Bone Joint Surg Am 88:16191640, 2006

54. Sasaki M, Asamoto S, Umegaki M, Matsumoto K: Cervical osteogenic degeneration in Japanese professional wrestlers and its relationship to cervical spine injury. J Neurosurg Spine 29:622-627, 2018

55. Simó M, Szirmai I, Arányi Z: Superior sensitivity of motor over somatosensory evoked potentials in the diagnosis of cervical spondylotic myelopathy. Eur J Neurol 11:621-626, 2004

56. Sumi M, Miyamoto H, Suzuki T, Kaneyama S, Kanatani T, Uno K: Prospective cohort study of mild cervical spondylotic myelopathy without surgical treatment. J Neurosurg Spine 16:8-14, 2012

57. Sun Y, Yu K, Wang H, Shen Y, Kong L, Zhang J: Diagnosis and treatment of hidden lesions in "mild" cervical spondylotic myelopathy patients with apparent symptoms. Medicine (Baltimore) 96:e7623, 2017

58. Tetreault LA, Dettori JR, Wilson JR, Singh A, Nouri A, Fehlings MG, et al: Systematic review of magnetic resonance imaging characteristics that affect treatment decision making and predict clinical outcome in patients with cervical spondylotic myelopathy. Spine (Phila Pa 1976) 38 (22 Suppl 1):S89-S110, 2013

59. Toledano M, Bartleson JD: Cervical spondylotic myelopathy. Neurol Clin 31:287-305, 2013

60. Tracy JA, Bartleson JD: Cervical spondylotic myelopathy. Neurologist 16:176-187, 2010

61. Tumialán LM, Pan J, Rodts GE, Mummaneni PV: The safety and efficacy of anterior cervical discectomy and fusion with polyetheretherketone spacer and recombinant human bone morphogenetic protein-2: a review of 200 patients. J Neurosurg Spine 8:529-535, 2008

62. Upadhyaya CD, Wu JC, Trost G, Haid RW, Traynelis VC, Tay B, et al: Analysis of the three United States Food and Drug 
Administration investigational device exemption cervical arthroplasty trials. J Neurosurg Spine 16:216-228, 2012

63. Vedantam A, Rajshekhar V: Does the type of T2-weighted hyperintensity influence surgical outcome in patients with cervical spondylotic myelopathy? A review. Eur Spine J 22:96-106, 2013

64. Virk SS, Phillips FM, Khan SN: Bundled payment reimbursement for anterior and posterior approaches for cervical spondylotic myelopathy: an analysis of private payer and Medicare databases. J Neurosurg Spine 28:244-251, 2018

65. Wang SJ, Ma B, Huang YF, Pan FM, Zhao WD, Wu DS: Four-level anterior cervical discectomy and fusion for cervical spondylotic myelopathy. J Orthop Surg (Hong Kong) 24:338-343, 2016

66. Wu JC, Chang HK, Huang WC, Tu TH, Fay LY, Kuo CH, et al: Radiological and clinical outcomes of cervical disc arthroplasty for the elderly: a comparison with young patients. BMC Musculoskelet Disord 20:115, 2019

67. Wu JC, Chen YC, Huang WC: Ossification of the posterior longitudinal ligament in cervical spine: prevalence, management, and prognosis. Neurospine 15:33-41, 2018

68. Wu JC, Chen YC, Liu L, Huang WC, Chen TJ, Lo SS, et al: Conservatively treated ossification of the posterior longitudinal ligament increases the risk of spinal cord injury: a nationwide cohort study. J Neurotrauma 29:462-468, 2012

69. Wu JC, Huang WC, Tu TH, Tsai HW, Ko CC, Wu CL, et al: Differences between soft-disc herniation and spondylosis in cervical arthroplasty: CT-documented heterotopic ossification with minimum 2 years of follow-up. J Neurosurg Spine 16:163-171, 2012

70. Wu JC, Ko CC, Yen YS, Huang WC, Chen YC, Liu L, et al: Epidemiology of cervical spondylotic myelopathy and its risk of causing spinal cord injury: a national cohort study. Neurosurg Focus 35(1):E10, 2013

71. Wu JC, Liu L, Chen YC, Huang WC, Chen TJ, Cheng H: Ossification of the posterior longitudinal ligament in the cervi- cal spine: an 11-year comprehensive national epidemiology study. Neurosurg Focus 30(3):E5, 2011

72. Wu JC, Liu L, Wen-Cheng H, Chen YC, Ko CC, Wu CL, et al: The incidence of adjacent segment disease requiring surgery after anterior cervical diskectomy and fusion: estimation using an 11-year comprehensive nationwide database in Taiwan. Neurosurgery 70:594-601, 2012

\section{Disclosures}

The authors report no conflict of interest concerning the materials or methods used in this study or the findings specified in this paper.

\section{Author Contributions}

Conception and design: Wu, Kuo. Acquisition of data: Kuo, Cheng. Analysis and interpretation of data: Chen, Cheng. Drafting the article: Chen, Kuo. Critically revising the article: Wu. Reviewed submitted version of manuscript: Wu. Approved the final version of the manuscript on behalf of all authors: Wu. Study supervision: $\mathrm{Wu}$.

\section{Supplemental Information Online-Only Content}

Supplemental material is available with the online version of the article.

Appendix Table. https://thejns.org/doi/suppl/10.3171/2019.5. SPINE18769.

\section{Correspondence}

Jau-Ching Wu: Neurological Institute, Taipei Veterans General Hospital, Taipei, Taiwan. jauching@gmail.com. 